Revista Triângulo

ISSN 2175-1609

\title{
DESENVOLVIMENO PROFISSIONAL DE UMA PROFESSORA DE MATEMÁtICA DURANTE A CONSTRUÇÃO DE OFICINAS PARA A EDUCAÇÃO INTEGRAL
}

\author{
PROFESSIONAL DEVELOPMENT OF A MATHEMATICAL TEACHER DURING THE CONSTRUCTION \\ OF WORKSHOPS FOR INTEGRAL EDUCATION
}
DESARROLLO PROFESIONAL DE UNA PROFESORA DE MATEMÁTICA DURANTE LA CONSTRUCCIÓN DE TALLERES PARA LA EDUCACIÓN INTEGRAL

\begin{abstract}
Luan Martins de Oliveira Programa de Pós-graduação em Educação Matemática da Universidade Federal de Ouro Preto.

E-mail: luanmartins55555@gmail.com

Edmilson Minoru Torisu

Programa de Pós-graduação em Educação Matemática da Universidade Federal de Ouro Preto. E-mail: etorisu@gmail.com
\end{abstract}

\section{RESUMO}

Este artigo apresenta resultados parciais de uma pesquisa de mestrado junto ao Programa de Pós-Graduação em Educação Matemática da Universidade Federal de Ouro Preto. Seu principal objetivo é desvelar indícios do desenvolvimento de uma professora de Matemática ao longo do processo de construção de oficinas para a Educação Integral. Para a coleta de dados foram utilizadas entrevistas semiestruturadas, antes e depois da criação e implementação das oficinas e outras entrevistas durante o processo de construção. Os resultados apontaram que o processo de construção das oficinas propiciou à professora vários momentos de reflexão sobre sua prática que nos deram vários indícios de desenvolvimento.

PALAVRAS-CHAVE: Desenvolvimento Profissional. Educação Integral. Educação Matemática.

\section{ABSTRACT}

This article presents partial results of a master's research linked to the Postgraduate Program in Mathematics Education of the Universidade Federal de Ouro Preto. The main objective is to unveil evidence of the professional development of a Mathematics teacher throughout the process of building workshops for Integral Education. For the data collection, semi-structured interviews were used, before and after the creation and implementation of the workshops and other interviews during the construction process. The results showed that the process of construction of the workshops gave the teacher several moments of reflection on her practice that gave us several indications of development.

KEYWORDS: Professional Development. Integral Education. Mathematical Education.

\section{RESUMEN}

Este artículo presenta resultados parciales de una investigación de maestría junto al Programa de Postgrado en Educación Matemática de la Universidade Federal de Ouro Preto. Su principal objetivo es desvelar indicios del desarrollo de una profesora de Matemáticas a lo largo del proceso de construcción de talleres para la Educación Integral. Para la recolección de datos se utilizaron entrevistas semiestructuradas, antes y después de la creación e implementación de los talleres y otras entrevistas durante el proceso de construcción. Los resultados apuntaron que el proceso de construcción de los talleres propició a la profesora varios momentos de reflexión sobre su práctica que nos dieron varios indicios de desarrollo.

PALABRAS-CLAVE: Desarrollo Profesional. Educación Integral. Educación Matemática. 


\section{INTRODUÇÃO}

Este artigo apresenta resultados parciais de uma pesquisa de mestrado junto ao Programa de Pós-Graduação em Educação Matemática da Universidade Federal de Ouro Preto. Pretende trazer à discussão o desenvolvimento profissional de uma professora de Matemática quando envolvida em um processo de construção de oficinas no contexto da Educação Integral, em parceria com um pesquisador ${ }^{1}$. A partir de respostas da professora a algumas entrevistas, o objetivo central do texto é desvelar indícios de seu desenvolvimento ao longo do processo.

Apresentamos, inicialmente, uma breve discussão sobre desenvolvimento profissional de professores e Educação Integral. Em seguida, apresentamos aspectos da metodologia, dados e algumas análises. Por fim, apresentamos algumas considerações finais.

\section{REFERENCIAL TEÓRICO}

\subsection{Desenvolvimento profissional de professores}

Ao concluir a graduação, o professor, embora tenha adquirido uma bagagem de conhecimentos para atuar na sala de aula, está longe de ser um profissional completo e amadurecido. Ao longo de sua carreira vai percebendo, paulatinamente, que seus conhecimentos e competências são insuficientes para lidar com todas as demandas que a ele se apresentam, o que gera a necessidade de aquisição de novos saberes que possam, em alguma medida, atenuar ou resolver esse incômodo. Esse processo que envolve a busca do professor pelo novo, por algo que o liberte de momentos nebulosos ou práticas cristalizadas e enrijecidas fazem parte do que podemos denominar 'desenvolvimento profissional do professor'.

A literatura apresenta muitas compreensões do que vem a ser esse desenvolvimento. Duas delas são recorrentes na literatura: uma, na qual desenvolvimento profissional é sinônimo de formação e outra, na qual esses conceitos são distintos. Na primeira, o desenvolvimento profissional é resultado de uma soma cujas parcelas são a formação inicial e a formação continuada. A formação inicial refere-se aos conhecimentos adquiridos na graduação que priorizam os conhecimentos acadêmicos e os conhecimentos didático-

\footnotetext{
${ }^{1}$ Primeiro autor
} 
pedagógicos. A formação continuada acontece em momentos posteriores à graduação, recorrentemente por meio de cursos de reciclagem que priorizam a transmissão de técnicas e conhecimentos, considerados relevantes e que servem como complemento à formação inicial para o professor em exercício (PASSOS et al, 2006). Um dos problemas que esse tipo de formação apresenta, na maioria das vezes, é seu caráter compulsório e instrumentalizador que nem sempre atende aos anseios e necessidades do professor. Essa Pedagogia tende a legitimar a razão instrumental na qual "os esforços de racionalização do ensino não se concretizam a partir de uma valorização dos saberes de que os professores são portadores, mas sim através de um esforço para impor novos saberes ditos "científicos" (NÓVOA, 1992, p. 16).

$\mathrm{Na}$ segunda forma de compreensão as formações, inicial e continuada, são componentes do desenvolvimento profissional, que também considera outros aspectos da vida dos professores como crenças e experiências anteriores (FERREIRA, 2003; PONTE, 1994). Nessa perspectiva, o professor é visto como 'alguém no mundo` e que, portanto, não está isento de suas influências. É uma perspectiva que não reduz o desenvolvimento à aquisição de conhecimentos. Nesse sentido, Charlot (2005, apud PASSOS et al, 2006, p. 196) considera que

Investigar o desenvolvimento profissional do professor, portanto, vai além da análise dos conhecimentos que adquire ao longo da vida profissional. Implica interpretá-lo, também, como sujeito com desejos, intenções, utopias, desilusões, que sofre os condicionamentos de seu contexto histórico-cultural. Ou seja, um sujeito de relação com o mundo, com as práticas escolares, com os conhecimentos institucionais, com as políticas públicas, com o seu tempo, com os outros e consigo mesmo.

Podemos perceber que nessa segunda perspectiva o desenvolvimento profissional do professor é influenciado por vários momentos de sua vida sem divorciá-los dos aspectos profissionais. É, de fato, uma perspectiva que enxerga o professor holisticamente e concordamos que isso é bastante coerente mas, ao mesmo tempo, um processo árduo e complexo.

De acordo com Ponte (2005), um dos fatores que mais influenciam o desenvolvimento profissional do professor é seu comprometimento pessoal. Ele precisa estar incomodado com as situações da sua prática diária para que surja o desejo por mudança. A mudança de postura do professor é primordial durante esse processo de aquisição de novos saberes. Outro fator 
importante apontado por Day (1999) como necessário para que ocorra desenvolvimento profissional do professor é a reflexão.

A discussão em torno das ideias sobre o professor reflexivo não é atual. John Dewey, em um livro publicado em 1900, já salientava a importância do exercício da ação reflexiva de professores. Mais recentemente, em 1983, Donald Shön trouxe novamente à baila essa discussão, no livro intitulado 'O profissional reflexivo', tornando-se referência sobre o assunto. Nesse livro, Schön considera alguns tipos de reflexão, dos quais destacamos a reflexão-na-ação e a reflexão-sobre-a-ação.

A reflexão-na-ação pode ser compreendida como um processo de tomada de decisão por parte dos professores quando envolvidos no processo de ensinar. Centra-se na identificação e solução rápida de problemas imediatos. A reflexão-sobre-a-ação é um processo que ocorre fora da ação, mas tendo-a como objeto principal para "análise, reconstrução e reformulação da prática no sentido de planejar o ensino e a aprendizagem em termos futuros. Ao contrário da reflexão-na-ação, este processo cria oportunidades para conversar com outros sobre o ensino" (DAY, 1999, p. 57). Esse compartilhamento de ideias, que pode suscitar produtivas discussões entre professores, ou entre professor e outros profissionais, pode influenciar de forma positiva o desenvolvimento profissional dos envolvidos.

Zeichner (2008) argumenta que a melhoria da prática profissional do professor se dá, inicialmente, a partir dessas ações, de sua prática do dia a dia e desconsidera que a prática reflexiva seja efetiva a partir das experiências de outrem, ou seja,

[...] O processo de compreensão e de melhoria de seu próprio ensino deve começar da reflexão sobre a sua própria experiência e que tipo de saber advindo unicamente da experiência de outras pessoas é insuficiente (ZEICHNER, 2008, p. 539).

Pode-se notar que esse autor defende a prática reflexiva quando o professor participa das ações do ensino em sua totalidade, desde a elaboração, passando pela aplicação na prática até a avaliação da mesma. Essas ideias corroboram as de Santos et al (2007), p. 4), quando caracterizam o professor reflexivo como

Um ser humano criativo, capaz de pensar, analisar, questionar a sua prática a fim de agir sobre ela e não como um mero reprodutor de ideias e práticas que lhes são exteriores. Por conseguinte, espera-se que o professor reflexivo seja capaz de atuar 
de uma forma mais autônoma, inteligente, flexível, buscando construir e reconstruir conhecimentos (SANTOS et al, 2007, p. 4).

$\mathrm{Na}$ contramão da discussão anterior, há fatores que podem influenciar negativamente o desenvolvimento profissional do professor. Stein (1998), citado por Ferreira (2003), considera que vários são os fatores que inibem o processo de mudança dos professores, dentre eles: a carga horária extensa, a vontade de trabalhar em isolamento, a dificuldade de trabalhar conjuntamente com outros professores. Acrescente-se a isso outros problemas apresentados por Day (1999), como a intensificação do seu trabalho, a ampliação da prestação de contas burocrática e contratual, a diminuição de recursos e o aumento do sistema administrativo, além da baixa remuneração destacada por Jesus e Santos (2004). Podemos acrescentar ainda, a esse rol de fatores que inibem o desenvolvimento profissional do professor, problemas de ordem pessoal. A todos esses elementos, que por vezes minam a motivação do professor para o seu desenvolvimento, Day (1999) denomina de erosão da autonomia do professor.

O objetivo desse artigo é desvelar indícios de desenvolvimento profissional de uma professora de Matemática durante o processo de construção e implementação de oficinas para a Educação Integral. Sendo assim, na próxima subseção apresentaremos um breve histórico sobre a Educação Integral.

\subsection{Educação Integral: breve histórico}

$\mathrm{O}$ ensino tradicional, que perdura no Brasil desde o século $\mathrm{XX}$, sempre defendeu um modelo de ensino no qual o saber do professor é algo incontroverso e a figura do aluno é de ouvinte passivo (MIZUKAMI, 1986). Devido às necessidades e problemas sociais que surgiram com o passar das décadas, despontou uma perspectiva educacional que reorganizou o currículo, ampliou significativamente as dimensões, os tempos, os espaços e as oportunidades formativas, ou seja, foi e é, com algumas ressalvas, uma educação na qual o contexto sociocultural dos educandos assume uma posição primordial na sala de aula e na escola (CAVALIERE, 2002). 
A Educação Integral ${ }^{2}$ mira o desenvolvimento em todas as dimensões - cultural, afetiva, cognitiva, emocional, física - dos jovens (ou das crianças e dos jovens) e essa ampliação acontece por toda vida, promovidas por experiências educativas que possam ser oferecidas para essas pessoas, através de projetos coletivos compartilhados com o contexto educacional (MOLL, 2009)

Atualmente, as ideias contempladas pelas concepções de Educação Integral (EI), possuem novos vieses metodológicos, políticos e epistemológicos, principalmente ligados à extensão da carga horária de permanência do estudante na escola (PESTANA, 2014). Nesse sentido, nas escolas brasileiras pode-se observar profissionais que, não necessariamente, são professores e professores realizando atividades que normalmente não são ditas escolares, como por exemplo: de higiene; alimentação; saúde (CAVALIERE, 2002). Esta forma de pensar a educação como uma educação de proteção social (PESTANA, 2014), por meio de atividades educacionais preliminares que resultaram na extensão da caga horária de permanência do aluno na escola foi influenciada pela precarização do ensino, que começa na escolarização primária no século XX, na qual era possível encontrar nas escolas pouca estrutura, redução da carga horária, multiplicação dos turnos e baixa qualidade dos professores. Além da precarização do ensino, outros fatores que influenciaram a extensão da carga horária foram o grande ciclo de urbanização e as políticas públicas dos anos 70,80 e 90, que retiraram a classe média do ensino público como consequência do aumento da privatização, acarretando assim baixa qualidade do sistema educacional brasileiro (CAVALIERE, 2002).

Ao longo dos anos, vários movimentos ligados à Educação Integral surgiram, dentre os quais o Anarquismo, o Integralismo e a Escola Nova. Cada um desses movimentos tinha defendia uma concepção de Educação Integral. Os anarquistas, por exemplo, propagavam o princípio da igualdade e da verdade humanas e faziam uma clara opção pelos aspectos emancipadores e progressistas da formação humana (COELHO et al., 2009). Os Integralistas, ao contrário, defendiam propostas para a Educação Integral voltadas para métodos de doutrina religiosa, disciplinar e patrióticos (LEITE; CARVALHO; VALADARES, 2010). Por outro

\footnotetext{
${ }^{2}$ Ver sobre as concepções de Educação Integral no Centro de Referência em Educação Integral, disponível em: $<$ http://educacaointegral.org.br/wp-content/uploads/2016/10/Posicionamento-CR-Set-2016.-final-paracoletivo.pdf> Acesso em: 03 de janeiro de 2018
} 
lado, os revolucionários do movimento Escola Nova, os escolanovistas, valorizavam a articulação entre a teoria e a prática nas ações da Educação Integral. Tais atividades propiciavam uma autonomia ao estudante na qual suas experiências cotidianas eram valorizadas. Estes vieses foram de encontro ao fazer pedagógico centrado na cultura intelectual abstrata que ocorria à época.

Em 1961, a Lei de Diretrizes e Bases da Educação Brasileira foi contemplada com algumas linhas que se associam às perspectivas de Educação Integral defendidas por Anísio Teixeira, que foi um dos precursores do movimento Escola Nova. Três anos depois, o Regime Militar foi instaurado no Brasil e os ideais de Educação Integral ficaram latentes. Eles ressurgiram no período da redemocratização (CAVALIERE, 2010), por intermédio de alguns projetos, como o projeto do Centros Integrados de Educação Pública (CIEPs), de Darcy Ribeiro (MIGNOT, 1989).

Nos anos 2000, as concepções de Educação Integral, que anteriormente já faziam parte de alguns projetos em vários estados e municípios do país, são ratificadas em programas do Governo Federal como, por exemplo, o Programa Mais Educação.

Em Minas Gerais, depois dos anos 2000 foram criados projetos de Educação Integral com o Programa de Educação em tempo Integral (PROETI), que buscou amparar o contexto escolar como um todo, além de promover ações para minorar problemas recorrentes na educação, como: dificuldade de aprendizagem nas disciplinas, retenção do aluno e evasão escolar (LEITE; CARVALHO; VALADARES, 2010).

Em 2012, a Secretaria do Estado de Minas Gerais reformulou algumas finalidades do PROETI, aproximando-o assim das propostas do Programa Mais Educação, na qual as atividades para a Educação Integral, que deveriam ser realizadas por no mínimo 3 horas diárias, começaram a ser divididas em campos do conhecimento. Em 2017, a Secretaria do Estado de Minas Gerais estreitou ainda mais as diretrizes da Educação Integral em Minas Gerais com as propostas do Mais Educação. Com esta nova configuração, o projeto com esta passou a se chamar Educação Integral e Integrada sendo suas atividades divididas em Macrocampos, ou seja, em áreas de trabalho (MINAS GERAIS, 2009; 2017).

No que segue, apresentaremos aspectos metodológicos do estudo. 


\section{MATERIAIS E MÉTODOS}

\subsection{Natureza do estudo e objetivo do artigo}

Para D'Ambrósio et al (2004), considera que em uma pesquisa qualitativa deve-se dar atenção às pessoas, suas ideias e procurar interpretar discursos e narrativas que estariam adormecidos. No presente estudo, demos atenção especial à falas e comportamentos de uma professora ao longo do processo de construção de oficias de Matemática. Isso está em consonância com as ideias de D'Ambrósio sobre pesquisas qualitativas.

Nesse artigo, nosso objetivo foi desvelar indícios de desenvolvimento profissional de uma professora de Matemática a partir da análise de dados coletados por meio de observações e entrevistas, antes, durante e depois da criação e implementação de oficinas de Matemática em aulas de Matemática. Para este artigo, dada a limitação de páginas, apresentaremos e analisaremos dados de uma das oficinas, denominada Oficina do Banco Imobiliário 3 .

\subsection{Sujeitos e contexto}

Nosso sujeito de pesquisa foi a professora Júlia ${ }^{4}$.O critério para escolha do sujeito era somente um: que fosse um professor ou professora de Matemática que trabalhasse na Educação Integral. Júlia foi a única que aceitou nosso convite. Em 2017, ano da pesquisa, ela tinha 35 anos, morava com o marido e a filha recém nascida. Lecionava na escola em que foi realizada a coleta de dados como professora efetiva de Matemática desde 2016. Sua primeira experiência com oficinas havia ocorrido durante a sua participação na escola Família Agrícola. Na Educação Integral, ela trabalhava há quatro anos. Era formada em administração pública e sua licenciatura em Matemática se deu por complementação de estudos em uma instituição privada. Muito comprometida com seu trabalho, era bem quista pelos alunos e conduzia a disciplina em sala de aula com 'pulso firme'.

A coleta de dados ocorreu no primeiro semestre de 2017 na escola em que Júlia trabalhava, localizada no centro da cidade de Ponte Nova, Minas Gerais. Essa escola é

\footnotetext{
${ }^{3}$ Esta oficina estará disponível, a partir de agosto, pelo link http://www.ppgedmat.ufop.br/index.php/producao/produtos

${ }^{4}$ Nome fictício
} 
estadual e atende aos Ensinos Fundamental I e II, possui laboratório de informática e sala de vídeo. As salas são amplas, mas pouco arejadas.

\subsection{Materiais e métodos}

Vieira e Volquind (2002) enfatizam que a oficina de ensino

Permite a criação de uma imagem real das situações-problema que envolvem os conteúdos; estimula o processo de qualificação do ensino, uma vez que possibilita realizar mudanças; adota metodologias que enfatizam procedimentos experimentais; seleciona e organiza conteúdos de acordo com os critérios de funcionalidade, utilidade e interesse dos alunos (VIEIRA; VOLQUIND, 2002, p.14).

Candau (1995), por sua vez, considera que a oficina é um espaço de construção coletiva do conhecimento, de análise da realidade, de confronto e troca de experiências. A nosso ver, tais experiências podem ser de vários tipos: cognitivas, afetivas e culturais, todas imbricadas. Nossas ideias relacionadas às oficinas, nesse estudo, foram nessa direção: concebidas como resultado de uma parceria entre pesquisador e a professora, levando em consideração as experiências de cada um e construindo novos conhecimentos.

Nesse processo, a sala de aula não foi isenta de interferências pela presença do investigador. Ele foi um agente que contribuiu para uma nova configuração desse espaço, inclusive nos momentos de aplicação das oficinas. Por isso, entendemos que o pesquisador foi um observador participante.

A observação participante é uma técnica na qual o observador se insere nas situações vivenciadas no campo de pesquisa (VIANNA, 2003). Alves-Mazzotti e Gewandsznajder (1998, p. 166) enfatizam que, nesse tipo de observação, o "pesquisador se torna parte da situação observada, interagindo por longos períodos com os sujeitos, buscando partilhar o seu cotidiano para sentir o que significa estar naquela situação".

Embora nosso foco fosse a professora, tudo que dizia respeito à sua prática era importante. Sendo assim, durante todo o período da pesquisa, construímos as oficinas em parceria, as implementamos em sala de aula, assistimos às aulas e tentamos ser parte daquele grupo.

Para capturar as impressões da professora durante a construção e implementação das oficinas utilizamos dois instrumentos principais: a entrevista e o que chamamos de arquivos de registros. Estes últimos substituíram o caderno de campo pois o pesquisador, envolvido na 
atividade, ao lado da professora, não tinha condições de fazer anotações imediatas. Dessa forma, os registros dos acontecimentos foram realizados em arquivos digitais.

A entrevista, clássica técnica utilizada em pesquisas qualitativas, foi utilizada nesse estudo com o objetivo de registrar as falas da professora relacionadas ao processo de criação das oficinas, de suas implementações em sala, de seus resultados junto aos alunos e às contribuições para sua prática. Foram três momentos de entrevistas gravadas em áudio: uma inicial, antes da elaboração em parceria das oficinas pedagógicas, uma que ocorria durante o processo de construção e outra ao final, após aplicação das oficinas.

As entrevistas, inicial e final, foram semiestruturadas e a entrevista durante a construção foi não estruturada, muito próxima de uma conversa informal. Na entrevista inicial procuramos ouvir as experiências de Júlia no ensino básico, suas metodologias para ensinar, suas compreensões sobre Educação Integral e, em particular, sobre oficinas. Na entrevista final, tínhamos interesse nas impressões de Júlia acerca de todo o processo de construção e implementação das oficinas, destacando pontos positivos e negativos. A entrevista que ocorreu durante a construção das oficinas tentou captar falas da professora de forma mais descontraída, sem muitas formalidades que pudessem aclarar suas impressões. As respostas e falas dessa professora nas entrevistas constituíram o corpus desse estudo.

\subsection{Consentimento e segurança}

À professora foi apresentado o Termo de Consentimento Livre e Esclarecido (TCLE) com informações sobre a pesquisa, a coleta de dados, riscos, garantia de anonimato, além de contatos dos pesquisadores, caso isso fosse necessário. Embora os estudantes não fossem nosso foco, aos pais foram apresentados TCLE para autorização da participação dos filhos na pesquisa. A coleta de dados só teve início após a recolha das assinaturas da professora e dos pais.

\section{ANÁLISE DOS DADOS E RESULTADOS}

Como informado na seção anterior, analisaremos os dados da oficina denominada Banco Imobiliário. Vale lembrar que a construção das oficinas foi muito importante, mas não 
foi nosso foco. O processo foi o contexto no qual procuramos indícios do desenvolvimento profissional de Júlia, nosso principal objetivo.

Antes de iniciarmos as discussões sobre como seria a oficina, uma primeira entrevista foi realizada com a professora. Nela procuramos saber um pouco sobre as experiências de Júlia e sobre sua relação com a Educação Integral e uso de oficinas nas aulas de Matemática. Outras entrevistas foram realizadas ao longo e no final do processo.

O primeiro contato de Júlia com a Educação Integral e Integrada havia ocorrido alguns anos antes, quando ela integrou um projeto na mesma escola em que lecionava. Sua ideia sobre Educação Integral era intuitiva e decorria de sua experiência e das aprendizagens com os supervisores escolares. Sua compreensão acerca de Educação Integral pode ser percebida na seguinte fala:

Eu prefiro como era antes, em que sentido? Eu tinha mais autonomia antes, por exemplo (hoje) não se pode usar o termo reforço, do tempo regular. Usando esse termo reforço, do tempo regular, eu conseguiria pegar as principais dificuldades dos meninos na sala de aula e dar, de fato, um reforço, um estudo dirigido. Lógico que eu não fazia isso toda semana, não fazia isso todo dia. Eu fazia isso pré-avaliação deles, entendeu? Ah, é semana de prova, a gente vai estudar. Como é que a gente vai estudar? Ai que entrava a Educação Integral, ensinava os meninos a estudar, a estudar em grupo, a estudar em dupla, individual.

A concepção de Educação Integral de Júlia estava muito relacionada à ideia de aulas de reforço, com orientações de como se estuda individualmente ou em grupo. Isso parece diferir da concepção de Educação integral defendida por Cavaliere (2002, p.1022). De acordo com a autora

Uma concepção de educação integral, que envolva múltiplas dimensões da vida das crianças e adolescentes, precisa de um tipo de escola onde ocorram vivências reflexivas [...]. Por isso, as escolas devem ser pensadas como locais onde se potencializem as atividades cooperativas e conjuntas. São essas atividades que levam efetivamente ao conhecimento, pois a aprendizagem é sempre indireta e se dá através de um meio social (CAVALIERE, 2002, p.1022).

O recurso às oficinas ocorria em alguns momentos da prática da professora, quase sempre com apoio de materiais encontrados na internet. Observemos o seguinte trecho da entrevista:

Pesquisador: Tem algum caderno pedagógico que te auxilia nessas oficinas ou você é quem as elabora?

Professora: Verdadeiramente falando, tem a internet. Sempre que eu preciso. Se quero trabalhar a tabuada eu vou lá na internet. Eu gosto por exemplo da Secretaria de Educação 
do Rio. Eles têm exemplos de oficinas que são feitos no regular que eu acho fantástica. A gente vê a experiência de outros professores que postam blogs ou outras coisas, né? Eu tento algo parecido com a nossa realidade, vou me envolvendo e vou ver se encaixa. Tem é ... dia a dia ... acho que é do Paraná ... também tem umas coisas muito bacanas.

Podemos reparar que, para Júlia, a ideia de oficina era de algo pronto, que poderia ser encaixado em sua situação de sala de aula. Talvez ainda fosse nebulosa a concepção de oficina como algo construído em conjunto, envolvendo outros professores e que leva em consideração as vivências dos estudantes. Um contexto de aprendizagens mútuas.

Uma característica da professora que chamou a atenção foi a preocupação com a disciplina dos alunos, aqui traduzida como 'pouca conversa'. Ela nos contou o seguinte fato ocorrido no início de sua carreira como professora:

Quando eu comecei a trabalhar, a primeira coisa que a inspetora falou comigo foi: lugar de aluno é na sala de aula. Se eu estiver na escola e você mandar um aluno para fora da sala, eu vou devolvê-lo.

A necessidade de manter a disciplina parece ter se tornado uma norma ditada pelos superiores. Essa visão pode ter engessado seu 'fazer' em sala de aula, restringindo-o ao uso do quadro, pois essa era uma forma de manter os alunos quietos. Essa crença talvez esteja associada à tão disseminada ideia de que um bom professor é aquele que mantém a disciplina em sala de aula. Relacionado a isso, vejamos a seguinte fala da professora:

Sempre gostei muito mais do quadro, por que eu consigo prender muito mais o aluno no quadro do que com o livro, questão de disciplina.

Práticas como essa da professora, que de alguma forma resolvem conflitos de forma rápida durante o processo de ensino podem ser vistas como resultado daquilo que Schön (1998) denomina reflexão-na-ação. Possivelmente, em algum momento de sua vida profissional, a professora se deparou com uma situação na qual os alunos estavam desatentos por causa da indisciplina. De forma mais ou menos consciente, contudo rápida, ela refletiu sobre uma solução imediata que resolvesse o conflito, mantendo-os atentos pelo uso do quadro. Isso gerou o que Schön (1987, apud DAY, 1999) denominou de conhecimento-naação. Esse novo conhecimento, por ter sido 'descoberto' pela professora e, sobretudo, por ter produzido o resultado esperado, foi adotado como prática recorrente em situações de indisciplina. Essa recorrência transformou essa prática naquilo que Yinger (1979, apud DAY, 1999) denominou de rotinas. As rotinas, por surtirem efeito na prática, muitas vezes 
padronizam a forma de agir em sala de aula e podem levar o professor à acomodação com consequente estagnação. Isso porque, a não reflexão sobre os efeitos dessa ação, ou reflexãosobre-ação em momento posterior, não permite que o conhecimento-na-ação seja submetido a um escrutínio de seu real efeito sobre a aprendizagem dos alunos.

Outra maneira possível de interpretar essa estratégia da professora para manter a atenção dos alunos é compreendê-la como o que Woods (1990, apud BOA SORTE, 2015), denomina estratégias práticas de sobrevivência. De acordo com Boa Sorte

[...] professores aprenderam a utilizar as estratégias de sobrevivência a partir da sua prática, do exercício diário do seu ofício, tentando dar conta de toda a complexidade que permeia o ensino e resolvendo os imprevistos surgidos em sala de aula e também na escola. [...] são estratégias que se revelam como parte integrante dos saberes experienciais, estão contidas neles e informam as mais diversas possibilidades de entender, lidar com e resolver os problemas que surgem no ofício do professor BOA SORTE, 2015, p. 15).

Outra resposta que mostra como, na visão da professora, a indisciplina a impedia de implementar uma nova prática é quando ela justifica o insucesso de suas oficinas. Isso se dava por "indisciplina, muito aluno na sala". Isso talvez a mantivesse em uma zona de conforto utilizando, preferencialmente, o quadro para manter a atenção da turma. Some-se a isso uma visão um pouco confusa do que vinha a ser oficinas na Educação Integral.

Contudo, a professora estava aberta a novas possibilidades e disse se sentir incomodada com sua prática em certo momento da primeira entrevista, quando a convidamos e apresentamos as ideias do trabalho de construção das oficinas em parceria:

Fui para casa balançando a cabeça, não está funcionando o que estou fazendo, então não adianta continuar do jeito que estou fazendo, não adianta, se eu estou fazendo um bolo sem fermento, ele não tá crescendo, ele não vai crescer sem fermento, qual é o fermento? Se o fermento é eu aprender a criar uma oficina com a amplitude dessa, por que vai funcionar com essa amplitude, por que se não for dessa amplitude, vai ser só um joguinho de matemática, eu sempre tive joguinho de Matemática, você entendeu?

Esse incômodo da professora ao avaliar a proposta e, em certa medida, comparar à sua prática, pode ser compreendida como uma perturbação. Ferreira (2003, p.37-38), baseada em Pehkönen e Torner (1999), considera que

[...] o desenvolvimento profissional e uma efetiva mudança na prática profissional dos professores devem ser precedidos do que denominam de perturbação de seus pensamentos e ações, de um comprometimento para resolvê-la, de uma visão do que 
eles gostariam de ver em suas classes (PEHKÖNEN; TURNER, 1999 apud FERREIRA, 2003, p. 37-38).

Embora nosso foco não fosse a criação das oficinas, foi nesse contexto que tentamos perceber indícios do desenvolvimento profissional dessa professora. Durante o processo de criação constatamos algo que era opinião de muitos em relação à professora Júlia: uma profissional muito comprometida e dedicada à sua profissão. Pode ser que o incômodo/perturbação com a prática, explicitado na resposta acima, tenha contribuído para a reflexão e maior engajamento da professora, configurando-se, a nosso ver, como um desejo por mudanças.

Ela assumiu papel fundamental na criação das oficinas em parceria com o pesquisador. Sugeriu regras, adaptações e se preocupou em fornecer informações sobre os alunos que pudessem trazer a oficina para perto de suas realidades. $\mathrm{O}$ comprometimento pessoal exibido pela professora é um dos fatores mais importantes para o desenvolvimento profissional do professor (PONTE, 1994).

Júlia não tinha o hábito de trabalhar em parceria com outros professores da escola. Em determinado momento da construção da oficina do Banco Imobiliário, o pesquisador precisou de algumas informações relacionadas à cidade de Ponte Nova como a distribuição espacial dos bairros, por exemplo, e que poderiam ser dadas pelo professor de Geografia. Após uma conversa, ambos, pesquisador e professora, chegaram à conclusão de que essa era uma boa oportunidade para convidar esse professor para participar do processo. Além dele, a professora de Português também foi convidada a contribuir, ajudando na redação das regras de modo que elas estivessem em linguagem clara para os estudantes. A nosso ver, uma fala de Júlia após esse trabalho com os outros professores mostra um novo olhar sobre os benefícios que um trabalho em parceria pode ter para ela. Ela disse:

[...] igual você pensou no professor de Geografia, agora estamos pensando na aula dele, e já pensei também na avaliação dele, enquanto uma oficina avaliativa [...]. Eles vão aprender que Geografia não é isolado de Matemática. Porque eu preciso aprender a ler para saber Matemática, eu preciso aprender Geografia para jogar um jogo de matemática. É isso que eu estou achando que vai abrir cabeça dos meninos, um leque maior. Essa é minha expectativa $[\ldots]$.

Júlia refletiu sobre o potencial da oficina até para servir como avaliação em Geografia - "já pensei também na avaliação dele, enquanto uma oficina avaliativa" - além de perceber 


\section{1 \\ Revista Triângulo \\ ISSN 2175-1609}

que a interdisciplinaridade pode revelar um novo mundo para os estudantes - "Eles vão aprender que Geografia não é isolado de Matemática" - "vai abrir a cabeça dos meninos, um leque maior". As reflexões a levaram a novas descobertas: novos modos de enxergar o trabalho em parceria com outros professores, leque maior de intercâmbios para os estudantes que revelam indícios de desenvolvimento profissional.

Isto está de acordo com as ideias de Pehkonen e Törner (1999, apud FERREIRA, 2003) quando os autores consideram que o espaço para compartilhar experiências e a vivência de situações criativas, como aquele que oferecemos à professora de Matemática e aos professores de Português e Geografia, podem conduzir à reflexão e pode favorecer o desenvolvimento/mudança do professor.

Em várias respostas dadas às perguntas da entrevista realizada após a construção e implementação da oficina do banco imobiliário, a professora apresentou indícios de mudanças no seu modo de pensar a sua prática. Ela avaliou e refletiu sobre seu background profissional e foi, ao longo da conversa, revelando suas impressões, seus novos modos de pensar e, quem sabe, futuros modos de agir. A nosso ver, é o que Schön (1998) denomina reflexão-sobre-aação. Vale lembrar que Day (1999, p. 57), baseado em ideias de Schön, acredita que a reflexão-sobre-a-ação parece "ajustar-se bem aos tipos de atividade de planificação coletivas", como ocorreu na criação das oficinas em parceria. Essas perguntas 'forçaram ' a professora a ocupar parte de seus pensamentos com aqueles voltados a uma avaliação crítica do que foi realizado: o que deu certo? O que deu errado? Qual o alcance? No que ela parece melhor comparada ao que era feito anteriormente?

Quando questionada sobre suas impressões gerais sobre todo o processo, a professora respondeu:

O processo foi muito, mais foi muito além de uma oficina. Quando você me propôs isso você, você me fez olhar para minha prática pedagógica. Então não tem como eu avaliar somente a oficina sem avaliar meu trabalho, você entendeu? Eu mudei inclusive com os meninos do regular, você entendeu? Então, assim, eu nunca tinha feito uma oficina com uma equipe tão grande, e isso achei Fantástico. A pré-disposição da equipe também achei Fantástico, entendeu? E a aceitabilidade dos meninos, isso hoje me surpreendeu.

Nessa resposta, podemos perceber que o processo de construção das oficinas fez Júlia refletir sobre sua prática e questioná-la, além de leva-la a enxergar o trabalho em equipe como algo bom. Mais que isso, a fez enxergar mudanças na sua prática até mesmo com os 
estudantes do ensino regular - "eu mudei com os meninos do regular". Em outro momento da entrevista ela ilustrou essa mudança com exemplos:

Um exemplo são as aulas que estou dando hoje no sexto ano, o sétimo ano, detalhe, já trabalhei com Slide Show em sala de aula, já trabalhei com vídeo aula em sala de aula, mas sempre foi uma aula, muitas assim (fazendo mais ou menos com a cabeça), os meninos assistem aquilo ali, como se tivessem assistindo uma televisão, né? Dessa vez eu fiz diferente. Cheguei na sala e expliquei como se assistir um vídeo, que você tem que estar com o caderno, tem que fazer uma anotação, comentei com eles o fato de existir uma, duas, três vezes para poderem absorver quando não estou entendendo.

A fala da professora mostra como o processo de construção impactou seu trabalho em sala de aula. Nesse exemplo, assistir a um vídeo assume novo sentido para os estudantes a partir da orientação da professora. Ela comentou, também, sobre novas formas de avaliação:

Fiz também, uma avaliação em três dias, uma avaliação para os meninos, bimestral valendo 10 pontos em 3 dias. Tá lá lançado no meu diário. Avaliação do conjunto dos números inteiros. Que avaliação é essa? Foi no slide. Foram 10 questões. Eu jogava no slide com tempo marcado e orientava, lia e fazia levantamento dos dados com os meninos, ia lá grifava para todos, lia com eles, e andando entre eles. [...] Eu lembro de uma aluna falar assim: nossa professora, gostei, mas demora muito pra gente fazer”. Eu falei assim: mas a gente tá fazendo respeitando o tempo do colega que tem mais dificuldade e o colega que tem mais dificuldade me chamava e eu explicava. [...] Eu não mostrava onde estava o erro, eu explicava o que ele tinha errado sem apontar lá, então assim eu senti que eles aprenderam muito mais nesses três dias avaliação, do que todo esse tempo, coisa que eu nunca tinha feito $[\ldots]$.

Embora não tenha havido, durante as oficinas, algum tipo de avaliação como o mencionado por Júlia na resposta acima, o processo como um todo parece tê-la encorajado a mudar e inovar. Uma nova forma de avaliar os estudantes, talvez mais atraente para eles, foi uma tentativa interessante que a professora nunca havia experimentado. Em suas palavras: "coisa que eu nunca tinha feito".

A forma como a professora enxergava as oficinas também sofreu mudanças. Inicialmente, as oficinas pareciam mais como aulas de reforço. Após a experiência vivida, Júlia não disse que construir oficinas e implementá-las é tarefa fácil. Entretanto, reconheceu que é importante construí-las e que a ajuda de parceiros contribui, sobremaneira, para a troca de ideias de modo a tornar a oficina apropriada para determinado público. A seguir, uma fala da professora que ilustra nossa análise:

[...] Não existe uma receita de bolo, na realidade nós demandamos tempo demais para isso, se você não tivesse me ajudado, eu teria levado muito mais tempo porque a minha parte ficou 
muito mais operacional, a gente reuniu, conversou e tudo mais, dei as minhas ideias, coloquei meus pontos de vista, porque eu conheço meusque meninos, né? E a gente não trouxe um 'trem' pronto para eles [...].

\section{CONSIDERAÇÕES FINAIS}

O desenvolvimento profissional do professor pode ser compreendido sob diferentes perspectivas. Neste artigo, tivemos a intenção de mostrar que ele é um processo complexo, árduo e que pode, em vários momentos, tirar o professor de sua zona de conforto. Tirá-lo dessa zona implica, de forma mais ampla, fazê-lo refletir sobre sua prática, por vezes cristalizada por anos de trabalho. A reflexão pode, por sua vez, contribuir para que surja no professor o desejo de mudança, tão importante para seu desenvolvimento.

A construção das oficinas não foi nosso foco nesse estudo. Contudo, o processo de construção e implementação em sala foi o contexto no qual pudemos observar indícios do desenvolvimento profissional da professora Júlia. A construção em parceria nos permitiu desvelar vários desses: grande comprometimento com o trabalho; reflexão sobre a prática que provocou o desejo por mudanças; nova percepção das possibilidades e vantagens do trabalho com outros colegas; novas descobertas para o 'fazer' em sala de aula em termos de avaliação, por exemplo; nova forma de compreensão do que vem a ser uma oficina de Matemática, agora mais voltada para a proposta apresentada nos documentos oficiais.

A partir desses resultados, embora parciais, acreditamos que quando o professor caminha para a mudança por desejo próprio, tendo liberdade para opinar e participando de todo o processo, que não é de caráter compulsório, o desenvolvimento pode ocorrer de forma mais efetiva.

\section{REFERÊNCIAS}

ALVES-MAZZOTTI, A. J; GEWANSDSZNAJDER, F. O debate contemporâneo sobre os paradigmas. In: A. J. Alves-Mazzotti \& F. Gewandsznjder. O método nas ciências naturais e sociais: pesquisa quantitativa e qualitativa. São Paulo: Pioneira, 1998.

BOA SORTE, P. Conceituando os Saberes Práticos de Sobrevivência. The Especialist, [S.1.], v. 36, n. 1, fev. 2015. ISSN 2318-7115. Disponível em:

$<$ https://revistas.pucsp.br/index.php/esp/article/view/21978

CANDAU, V. et al. Oficinas pedagógicas de Direitos Humanos. Petrópolis: Vozes, 1995. 
CAVALIERE, A. M. Educação Integral: uma nova identidade para a escola brasileira. Educação e Sociedade, v. 23, n. 81, p. 247-270, 2002.

COELHO, L. M. C. C; MARQUES, L. P; BRANCO, V. Políticas públicas municipais de educação integral e $(\mathrm{m})$ tempo ampliado: quando a escola faz a diferença. Ensaio: Avaliação e Políticas Públicas em Educação, Rio de Janeiro, v. 22, n. 83, p. 355-378, abri./jun. 2014.

D’AMBRÓSIO, U. Prefácio. In Borba, M. C. \& Araújo, J. L. (Eds.) Pesquisa Qualitativa em Educação Matemática. Belo Horizonte: Autêntica, 2004.

DAY, C. Desenvolvimento profissional de professores: os desafios da aprendizagem permanente. Porto Editora, 1999.

FERREIRA, A. C. Metacognição e desenvolvimento profissional de professores de Matemática: uma experiência de trabalho colaborativo. Tese (Doutorado em Educação) Universidade Estadual de Campinas, Campinas, 2003.

JESUS, S. N. de, S.; SANTOS, J. C. V. Desenvolvimento Profissional e Motivação dos Professores. Educação, vol. XXVII, núm. 52, janeiro-abril, 2004, pp. 39-58. Pontifícia Universidade Católica do Rio Grande do Sul, Porto Alegre, Brasil.

LEITE, L. H. A; CARVALHO, L. D; VALADARES, J. M. (Org.). Educação Integral e Integrada: Módulo II - Desenvolvimento da Educação Integral no Brasil. Belo Horizonte: Faculdade de Educação - UFMG, 2010. 144 p. Disponível em: $<$ https://educacaointegralintegrada.files.wordpress.com/2012/03/material-mc3b3dulo-2-edintegral.pdf $>$. Acesso em: 04 fev. 2018.

MIGNOT, A. C. V. CIEP - Centro Integrado de Educação Pública - alternativa para a qualidade do ensino ou nova investida na educação? Em Aberto, Brasília, ano 8, n. 44, outdez. 1989. P. 45-63.

MINAS GERAIS. Centro de Referência Virtual. Cartilha Tempo Integral, 2009. Disponível em: <http://crv.educacao.mg.gov.br>. Acesso em: out. 2016.

MINAS GERAIS. Documento Orientador das Ações de Educação Integral no Estado de Minas Gerais: Ampliação de Direitos, Tempos e Espaços Educativos - Versão II - 14 De Abril De 2015 Disponível em:

$<\mathrm{http}: / /$ http://files.comunidades.net/alfabetizacaotempocerto/EDUCACAO_INTEGRAL_SEE _MG_14.04.2015_2_VERSAO.pdf> Acesso em: abr. 2016;

MIZUKAMI, M. G. N. Ensino: as abordagens do processo: Temas básicos de Educação e Ensino. São Paulo: Editora Pedagógica e Universitária, 1986.

MOLL, J. Educação integral: texto referência para o debate nacional. Brasília: MEC/SECAD, 2009. Mais Educação. 
NÓVOA, A. Formação de professores e profissão docente. In NÓVOA, A. Os professores e a sua formação. Lisboa: Dom Quixote, 1992. ISBN 972-20-1008-5. pp. 13-33.

PASSOS, C. L. B; NACARATO, A. M; FIORENTINI, D; MISKULIN, R. G. S; GRANDO, R. C; GAMA, R. P; MELO, M. D. Desenvolvimento profissional do professor que ensina Matemática: Uma meta-análise de estudos brasileiros. Quadrante, v. 15, n. 1, p. 193-219, 2006.

PESTANA, S. F. P. AFINAL, O QUE É EDUCAÇÃO INTEGRAL? Revista

Contemporânea de Educação, Universidade Federal do Rio de Janeiro, v. 9, n. 17, p. 24-41, out. 2014.

PONTE, J. P. A formação do professor de Matemática: Passado, presente e futuro. In L. SANTOS, L. A. P. CANAVARRO, A. P.; BROCARDO, J. (Eds), Educação Matemática: Caminhos e encruzilhadas, Lisboa: APM, p. 267 - 284, 2005.

PONTE, J. P. O desenvolvimento profissional do professor de matemática. Educação e Matemática, n. 31, p. 9-12, 1994.

SANTOS, A.; LUSARDO, R. C; CESTARO, P. M. R. Professor reflexivo: gênese e implicações atuais. Simpósio Espaço e Educação. Anais do I Simpósio Espaço Educação. Juiz de Fora, Minas Gerais, 2007. Disponível em:

$<$ http://www.ufjf.br/espacoeducacao/simposio-espaco-educacao/anais-do-i-simposio-espacoeducacao/comunicacoes-coordenadas/cc05-infancia-e-educacao-coordenadora-leastahlschmidt-pinto-silva/>

SCHÖN, D. Educando o profissional reflexivo: um novo design para o ensino e a aprendizagem. Porto Alegre: Artes Médicas, 1998.

VIANNA, H. M. Pesquisa em Educação: a observação. Brasília: Plano Editora, 2003.

VIEIRA, E; VOLQUIND, L. Oficinas de ensino: O quê? Por quê? Como? 4. ed. Porto Alegre: Edipucrs, 2002.

ZEICHNER, K. M. Uma Análise Crítica sobre a Reflexão, como Conceito Estruturante na Formação Docente. Educação \& Sociedade, v. 29, n. 103, 2008; 